\title{
The Effects of Extracts of Lantana camara (L.) and Azadirachta indica (A. Juss) on the Population Dynamics of Plutella xylostella, Brevicoryne brassicae and Hellula undalis on Cabbage
}

\author{
P. K. Baidoo ${ }^{1} \&$ J. I. Adam ${ }^{1}$ \\ ${ }^{1}$ Department of Theoretical and Applied Biology, Kwame Nkrumah University of Science and Technology, \\ Kumasi, Ghana \\ Correspondence: P. K. Baidoo, Department of Theoretical and Applied Biology, Kwame Nkrumah University of \\ Science and Technology, Kumasi, Ghana. E-mail: pkbaidoo2002@yahoo.com
}

Received: April 6, 2012 Accepted: July 11, 2012 Online Published: July 26, 2012

doi:10.5539/sar.v1n2p229 URL: http://dx.doi.org/10.5539/sar.v1n2p229

\begin{abstract}
The effects of ethanolic extract of neem, Azadirachta indica (Meliaceae), seeds and petroleum ether extract of Lantana camara leaves (Verbenaceae) on the populations of three cabbage pests, Plutella xylostella, Brevicoryne brassicae and Hellula undalis were studied. The study was conducted between January and April 2008. Extracts of the two plants were sprayed on cabbage plants to control these pests. A standard synthetic chemical insecticide (Mektin) was used as reference product. The experiment was conducted in a randomized complete block design and each treatment was replicated four times. The effects of plant extracts on the population dynamics of the pests' species, the level of infestation and yield were assessed. Significantly more of the pests infested the control plants than the treated plants $(P<0.01)$. The mean weight of cabbage heads on the sprayed plots was significantly heavier than that of the control unsprayed plots. The use of $A$. indica seeds and L. camara leaf extracts increased yield by $37.05 \%$ and $25.80 \%$, respectively. Spraying the cabbage plants with the plant extracts significantly reduced the numbers of pests compared with the control plants. The use of these plant extracts can be incorporated into an overall control programme of these pests.
\end{abstract}

Keywords: Azadirachta indica, ethanolic extract, Lantana camara, petroleum ether, Plutella xylostella, mektin

\section{Introduction}

Cabbage (Brassica oleracea L.) is an important leafy vegetable widely cultivated in many countries in Africa for food and fodder. It is a primary source of roughage in the diet of humans (Ensminger \& Ensminger, 1986). However, cabbage is susceptible to insect pest infestation in the field, which causes great loss to the growers. These pests infest the plants at different stages of their growth and cause serious damage to the head of the crop as well as the wrapper leaves which reduces its marketability (Eigenbrode et al., 1990). The most common pests of cabbage are the diamondback moth, Plutella xylostella, cabbage aphid, Brevicoryne brassicae (Norman, 1992) and the cabbage webworm, Hellula undalis. These pests affect all the growth stages of the plant. Even though many insect pests attack cabbage, the most destructive pest is $P$. xylostella. Generations of $P$. xylostella overlap throughout the warmer months of the year (Gullan \& Crantson, 1994).

Synthetic chemical insecticides have been used for many years in the control of these pests. The continuous and improper use of such chemical insecticides often results in the development of insect resistance to these insecticides, food and groundwater contaminations. When insecticide resistance develops, management of the pest becomes even more difficult. As a result of the above problems there is the need to find alternative and suitable methods for the control of these pests to bring about increased crop production. The use of plant derivatives as an alternative to chemical insecticides has been studied throughout the world. Over 2000 plant species have been reported to possess pest control properties (Ahmed et al., 1984). Two of such plants are Azadirachta indica and Lantana camara. Many plant metabolites have been characterized as having defensive mechanisms against insect pests. These include azadirachtin from the neem plant and lantanine from L. camara. Extracts from the leaves of $L$. camara exhibit antimicrobial, fungicidal, insecticidal and nematicidal activities (Begum et al., 2000). The neem tree, Azadirachta indica, has been demonstrated to possess insecticidal properties. This is because several chemicals in its leaves and seeds have been shown to be effective against 
many agricultural insect pests (Schmutterer et al., 1981). According to Ivbijaro (1983), the use of ground neem seeds on Sitophilus oryzae on stored maize completely halted post-embryonic development. Azadirachtin is the major biologically active substance in the neem tree which interferes with the biology of a number of insects. Azadirachtin has an antifeedant, sterilizing and morphogenic effect on target pests' species. It is structurally similar to the insect hormone, ecdysone which controls the process of moulting. Azadirachtin appears to block the insect's ability to release this hormone (Gullan \& Cranston, 1994). The process of moulting is therefore hindered, thus breaking the insect's life cycle (Schmutterer, 1998). The application of botanicals in the management of insect pests has received more attention because they offer a more environmentally friendly and sustainable alternative to synthetic insecticides. The study therefore assessed the effectiveness of extracts from neem, A. indica seeds and L. camara leaves in the management of some pests of cabbage.

\section{Materials and Methods}

\subsection{Preparation of Plant Extracts}

Ripe neem, A. indica, seeds were harvested from neem plants in Cape Coast in the coastal region of Ghana. They were dried to a constant weight under shade, away from direct sunlight to prevent photo-oxidation of the active ingredients. Three kilogrammes of the dried seeds were ground into a fine powder followed by extraction with ethyl alcohol. Similarly, $1 \mathrm{~kg}$ fresh leaves of Lantana camara were dried to a constant weight. The dried leaves were milled with an electric blender. One litre of petroleum ether was added to the milled leaves in a conical flask, placed on mechanical shaker and shaken for $8 \mathrm{hrs}$. The extract was filtered under suction and concentrated in a rotary evaporator. The extracts were stored in a cupboard away from light until ready to use.

\subsection{Nursing and Transplanting of Cabbage Seedlings}

Cabbage, Brassica oleracea (var. oxyllus) seeds were nursed in the Greenhouse in wooden boxes, $60 \mathrm{~cm}$ x $60 \mathrm{~cm}$ and $8 \mathrm{~cm}$ deep. The seedlings were transplanted 3 weeks after germination. The experiment was conducted in a randomized complete block design with four treatments each of which was replicated four times. The treatments were neem seed extract, L. camara leaf extract, a chemical insecticide, Mektin (Active ingredient $18 \mathrm{~g} / 1$ Abamectin) for comparison with the plant extracts and a control. Each plot contained 30 plants with 5 rows and 6 columns. The spaces between both the rows and columns were $75 \mathrm{~cm}$ each. Two weeks after transplanting, the plant extracts were sprayed onto the plants on the various plots. Neem seed extract was applied at a rate of $10 \mathrm{ml}$ of the extract in 1 litre of water. The same concentration was used for L. camara. Mektin was applied at the rate of $10 \mathrm{ml} /$ litre of water. A second application was done 2 weeks after the first one and the third one was two weeks after the second one. The control plants were left unsprayed.

\subsection{Data Collection}

The plants were carefully observed weekly for the incidence of pests. The simple random sampling method was used to sample infested plants. The various pests' species were identified and their numbers counted and recorded for each treatment. Plants recorded as having been infested were tagged to prevent them from being sampled the following week. Data collection continued for 8 weeks. Percent infested plants on each plot and for each treatment was determined and means were computed. Percent infestation was calculated from the following formula:

$\%$ infestation $=$ Number of infested plants/ Total number of plants on a plot $* 100 \%$

For yield analysis, five cabbage heads were randomly selected from each bed for each treatment, weighed and the mean for each treatment was calculated.

\subsection{Data Analysis}

Ananlysis of variance (ANOVA) was performed on the data using the general linear model (GLM) procedure of SAS (SAS, Institute, 1989). Where the difference was significant, the means were separated using the Student Neuman Keul's (SNK) test. Significant difference was set at $P \leq 0.05$.

\section{Results}

\subsection{Insect Pests on Cabbage}

A number of insect pests were found on the plants. These included P. xylostella, B. brassicae, Hellula undalis, the cabbage looper Tricoplusia ni, the variegated grasshopper, Zonocerus variegatus and the African mole cricket Gryllotalpa africana. These pests appeared at different stages of growth of the plants. B. brassicae was the first to attack the plants and this was 1 week after transplanting (WAT). They were found on all the plots. However, after spraying with the various insecticides their numbers were significantly reduced on the treated plants (Figure 1), $(P<0.01)$. Infestation by B. brassicae on all the treated plots did not differ significantly $(P>$ 
$0.05)$.

P. xyostella infestation was observed 2 WAT. Infestation was rather high; reaching its peak numbers 3 weeks after spraying (WAS) on the control plants. Even though their numbers decreased with the growth of the plants, they remained relatively higher on the control plants (Figure 2) until harvest. Significantly more of them were recorded on the control plants than the treated plants. A. indica treated plants recorded the least number of $P$. xylostella. However, the difference in the pest numbers on the treated plants was not significant $(P>0.05)$. Larvae of Hellula undalis were detected on the plants 4 weeks after spraying (WAS) (Figure 3). With the exception of the neem treated plants, this pest remained on all the plots until harvest even though their numbers were significantly higher on the control plants (Figure 3$)(P<0.01)$. The numbers of H. undalis in the treated plants did not differ significantly.

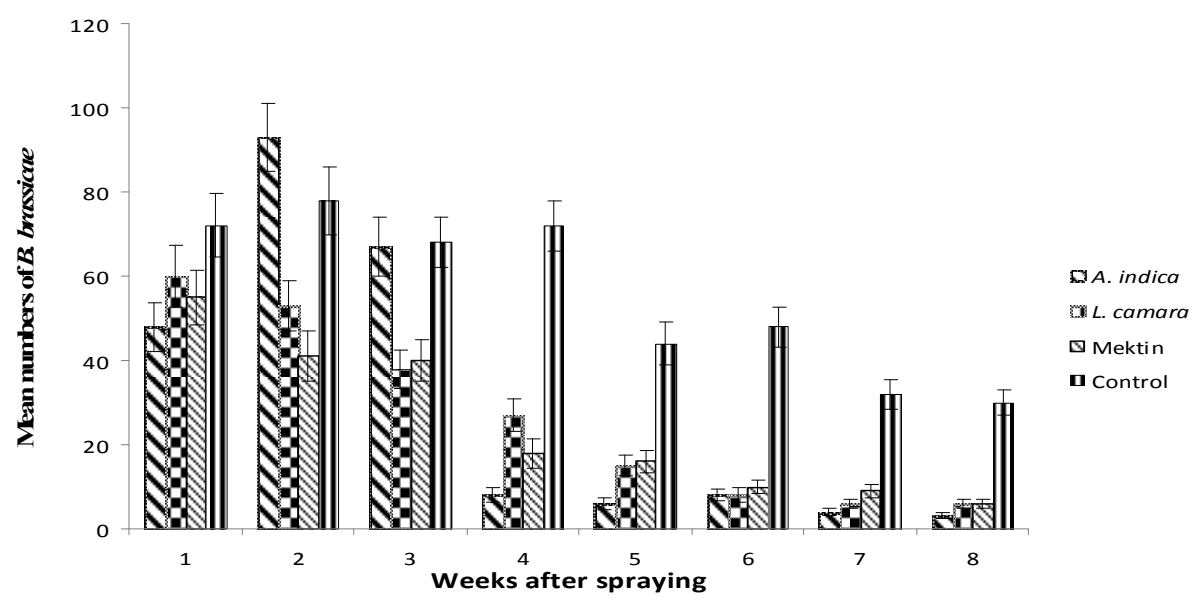

Figure 1. Mean numbers of $B$. brassicae after spraying

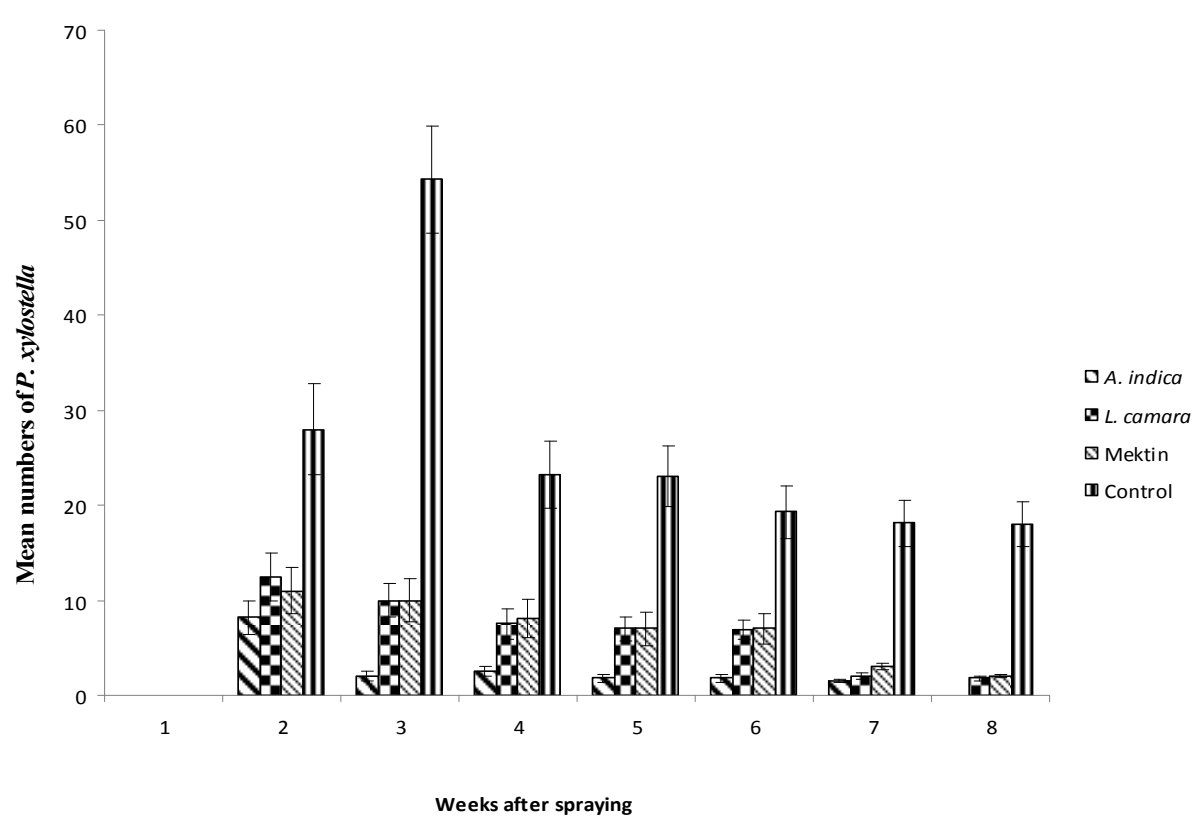

Figure 2. Mean numbers of Plutella xylostella counted after spraying 


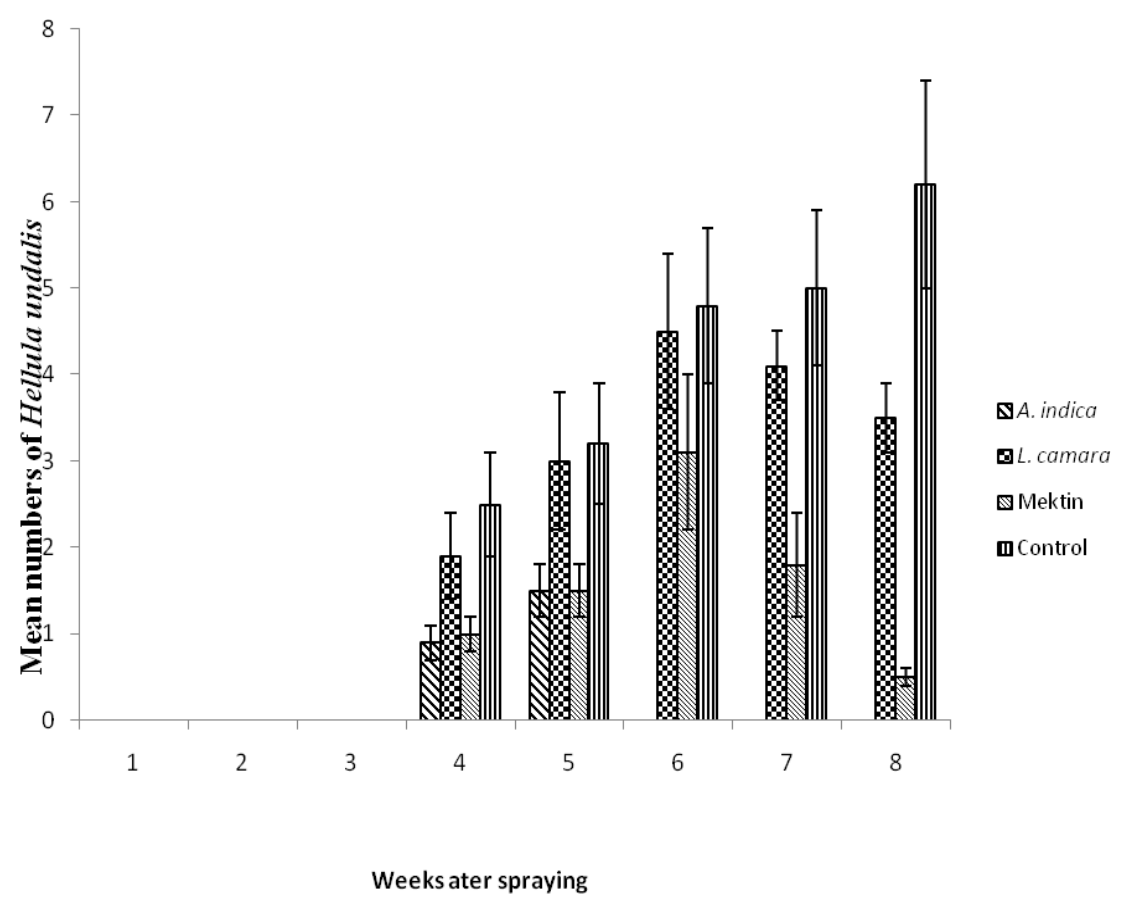

Figure 3. Mean numbers of Hellula undalis collected after spraying

\subsection{Percentage Infestation}

Percentage infestation on the plants ranged from 18.2 in mektin -treated plants to 88.7 in the control plants (Table 1). Percent infestation was significantly larger on the control plants than on the treated plants $(P<0.01)$. A significant difference was observed between the neem-treated plants and L. camara-treated plants $(P<0.05)$, but the difference between neem-treated and Mektin-treated plants was not significant $(P>0.05)$.

\subsection{Weight of Cabbage Heads}

Cabbage heads from the neem-treated plots were the heaviest with a mean weight of $1.23 \mathrm{~kg}$. The control plants which recorded the heaviest insect infestation had a mean weight of $0.89 \mathrm{~kg}$ (Table 1). The difference was significant $(P<0.01)$. However, the difference in the weight of cabbage heads on the treated plots did not differ significantly $(P>0.05)$. The use of neem extract and $L$. camara increased the weight of the cabbage heads by $37.05 \%$ and $25.80 \%$, respectively compared with the control plants.

Table 1. Effect of plant extracts on the populations of major cabbage pests, the levels of infestations and weight of cabbage heads

\begin{tabular}{cccccc}
\hline Treatments & B. brassicae & P. xylostella & H. undalis & \% Infestation & Mean wt. of head (kg) \\
\hline A. indica & $37.8^{\mathrm{a}}$ & $24.3^{\mathrm{a}}$ & $2.0^{\mathrm{a}}$ & $23.6^{\mathrm{a}}$ & $1.23^{\mathrm{a}}$ \\
L. camara & $105.6^{\mathrm{b}}$ & $31.5^{\mathrm{a}}$ & $3.7^{\mathrm{a}}$ & $34.5^{\mathrm{b}}$ & $1.12^{\mathrm{a}}$ \\
Mektin & $95.7^{\mathrm{b}}$ & $26.3^{\mathrm{a}}$ & $1.7^{\mathrm{a}}$ & $18.2^{\mathrm{a}}$ & $1.15^{\mathrm{a}}$ \\
Control & $435.5^{\mathrm{c}}$ & $166.6^{\mathrm{b}}$ & $9.7^{\mathrm{b}}$ & $88.7^{\mathrm{c}}$ & $0.89^{\mathrm{b}}$ \\
\hline
\end{tabular}

Within the same column means followed by the same letter are not significantly different $(P>0.05)$.

\section{Discussion}

The use of natural plant products and their analogues have been considered for the management of agricultural insect pests. This is due to the fact that they are less detrimental to the environment than synthetic chemical insecticides. The appearance of the various pests' species affected the growth of the plants. Even though some of the plots were sprayed with control agents, all the plots recorded some level of pest infestation. Before the 
application of the insecticides, all the plots were infested with B. brassicae and P. xylostella. These insects caused stunted growth, malformed and distorted leaves. These effects resulted in reduced head weight; especially in the control plants. The feeding activities of P. xylostella in particular resulted in windowpanes and holes in the leaves. Both B. brassicae and P. xylostella were found under the leaves, thus being protected from the intense heat during the day.

The consistent and significant decrease in the numbers of pests on the treated plots indicates the effectiveness of the plant extracts. The fact that no significant difference was observed between the numbers of the pests on the plots treated with the plant extracts indicates that the two plant extracts were equally effective in the management of these pests. The reduction in pests' numbers was due to the antifeedant properties of the extracts which caused mortality. This has been reported in the case of $A$. indica (Arnasson et al., 1985; Tanzubil, 1995) and for L. camara (Kulkarni et al., 1997; Mehta et al., 1995). In A. indica the insecticidal property is due to the triterpernoids, azadirachtin and salanin (Schmutterer et al., 1981; Schmutterer \& Ascher, 1984). In L. camara, however, the triterpenoid lantadene is responsible for its antifeedant properties (Mehta et al., 1995). Once ingested, their effects are to prevent food utilization by susceptible insects and therefore mortality results from starvation. From the numbers of $H$. undalis collected, it appears that this pest is more difficult to control, even with chemical insecticides. Unlike B. brassicae and P. xylostella, H. undalis was completely protected by the wrapper leaves from the effects of the insecticides. This explains why relatively high numbers were obtained on the plants even after insecticide application.

\section{Conclusion}

The use of plant extracts with insecticidal properties has the potential of reducing the effects of insect pests of agricultural crops. These can be of importance to the resource-poor farmers in many areas of the developing world. The significant reduction in pests' numbers on the treated plants was an indication that they can be used as alternatives to chemical insecticides. Even though various pest species attacked the cabbage plants, $P$. xylostella caused the most serious damage. It was the main cause of reduction in weight of cabbage heads.

\section{References}

Ahmed, S., Grainage, M., Hylin, J. W., Mitchel, W. C. \& Litsinger, J. A. (1984). Some promising plant species for use as pest control agents under traditional farming systems. In: Proceedings of the Second International Neem Conference (Edited by Schmutterer H. and Ascher K. R. S.). pp. 565-580.

Arnason, J. T., Philogere, B. J. R., Donsker, N., Hudor, M., McDougall, C., Fortier, G., ... \& Nozzolillo, C. (1985). Antifeedant and insecticidal properties of azadirachtin against the European corn borer Ostrinia nubilalis. Ent. Exp. Appl, 38, 29-34. http://dx.doi.org/10.1111/j.1570-7458.1985.tb03494.x

Begum, S., Wahab, A., Siddiqui, B. S., \& Qamar, F. (2000). Nematicidal Constituents of the aerial parts of Lantana camara. Journal of Natural Products, 63, 765-767. http://dx.doi.org/10.1021/np9903548

Eigenbrode, D. E., Shelton, A. M., \& Dickson, M. H. (1990). Two types of resistance to the diamondback moth (Lepidoptera:Plutellidae) in cabbage. Environmental Entomology, 19(4), 1080-1090.

Ensminger, A. H., \& Ensminger, M. K. J. (1986). Food for Health: A Nutrition Encyclopaedia Clovis. California, Pegus Press. pp. 201-218.

Gullan, P. J. \& Crantson, P. S. (1994). Insects : A. Outline of Entomology. Chapman and Hall London, U. K. p. 491.

Ivbijaro, M. F. (1983). Toxicity of neem seed Azadirachta indica (A. Juss) to Sitophilus oryzae (L.) in stored maize. Protection Ecology, 4, 353-357.

Kulkarni, N., Joshi, K. C., \& Gubta, B. N. (1997). Antifeedant property of Lantana camara var aculeata and Aloe vera leaves against the teak skeletonizer Eutectona machaeralis Walker (Lepidoptera: Pyralidae). Entomology, 22(1), 61-65.

Mehta, P. K., Vaida, D. N., \& Kashyap, N. P. (1995). Antifeedant properties of some plant extracts against brinjal hadda beetle Henosepilachna vigintioctopunctata. Journal of Entomological Research, 19(2), 147-150.

Norman, J. C. (1992). Tropical Vegetable Crops. Arthur H. Stockwell ltd., Devon. P. 252.

SAS Institute, Inc. (1989). SAS/STAT User's Guide, Version 6, Fourth Edition, Vol. 1, SAS Institute., Cary, NC., p. 943.

Schmutterer, H. (1998). The potentials of neem trees. The Weekly Spectator (October 31 -November 6 1998) At a Serminar at Dodowa, Ghana. p. 2. 
Schmutterer, H., \& Ascher, K. R. S. (1984). Proceedings of the Second Neem Conference (Rauischolzhausen, 1983) GTZ Eschborn. p. 587.

Schmutterer, H., Ascher, K. R. S., \& Rembold, H. (1981). Proceedings of the First Neem Conference (GTZ Rottach-Egern, 1980). p. 297.

Tanzubil, P. B. (1995). Effects of neem Azadirachta indica (A. Juss) extracts on food intake and utilization in the African armyworm, Spodoptera exempta (Walker). Insect Science and its Application, 16(2) 167-170. 